\title{
Memory for the intentions of sentences*
}

\author{
ROBERT J. JARVELLA $†$ \\ The Rockefeller [niversity. Vew York, New York 10021 \\ and \\ JOY GOLDMAN COLLAS \\ Case Western Reseri'e University. Cleveland, Ohio 44106
}

\begin{abstract}
Memory for the intentions of sentences was studied in two recognition tasks. In each study. Ss first acter out a dialogue written for two people. They then judged whether certain sentences in a second dialogue were the same as or different from previous sentences (Experiment I) or chose between two intentions suggested for some previous sentences (Experiment II). Sentences which were repeated with the same intention across the two dialogues were judged as being the same significantly more often than were sentences repeated with a different intention. The appropriate intention for each of these sentences was also usually chosen. In both studies, Ss appeared to remember more accurately the sentences they had spoken themselves than they did those that were addressed to them.
\end{abstract}

What a sentence means and what someone means by saying it relate to its propositional content. on the one hand. and to its communicative function, on the other (Austin. 1962: Searle, 1965: Miller, 1970). The first aspect of sentence meaning, dealing with propositional content, has been quite widely studied in linguistics and psycholinguistics, particularly with respect to sentence form. Generally speaking. content appears to be remembered from speech after form is largely forgotten. For example. once a target sentence has been followed by another sentence of discourse with novel content. its verbatim form is neither very well recalled nor recognized (Jarvella: 1971. 1973). However. even after several intervening sentences. the content of a sentence is usually remembered well enough for listeners to detect substantial changes in a comparison item (Sachs. 1967: Mathewson \& Keeney. 1971). Inferences based on content may also be obtained from listeners well after the time when a sentence is initially presented (Bransford. Barclay. \& Franks. 1972). These findings suggest that the propositional content of sentences may be a significant part of what is retained from heard speech.

The second aspect of sentence meaning, having to do with a speaker's intention for saying particular things. has been considered mainly in philosophy (Grice. 1957: Alston. 1964; Strawson. 1964) and in social psychology (see Robinson. 1972, for a review). On the one hand. a speaker"s intention is likely to be reflected in the way in which he says something. Searle (1965) and Miller (1970) have suggested that both prosodic and syntactic cues may help listeners to recognize the "illocutionary force." or intentional meaning, of sentences used in conversations. Declarative and interrogative forms. for

\footnotetext{
*This research was supported in part by Grant MH-22134 to the senior author from the National Institute of Mental Health. The authors also wish to thank George $\mathrm{A}$. Miller for commenting on a previous draft of this paper.

$\rightarrow$ Requests for reprints should be sent to Robert J. Iarvella. The Rockefeller Iniversity. 66th Street and Fork Avenue. Ne's York. New York 10021.
}

example, may usually be intended as statements and questions, respectively. However, each form may have quite different functions. depending on the linguistic and situational context in which it occurs. Thus, in saying. "The door is open," a speaker might functionally not be making a statement at all, but be inviting his listener to enter a room or be telling him to close the door. Similarly. in some circumstances an interrogative form might have the force of a denial rather than of a request for information.

The present research was directed at exploring whether Ss who had acted out a conversation between two pecple would remember the intentions for some of the sentences that they had spoken or that had been addressed to them. In each of two experiments, pairs of female college students acted out several dialogues. After each acted version. the Ss either judged whether particular sentences from a comparison dialogue were the same as or different from acted sentences (Experiment I) or chose between two intentions suggested for some of the acted sentences (Experiment II). It was hypothesized that the Ss would recognize the intentional as well as the propositional meaning of the sentences as they acted out each dialogue. and would retain this information in some form in memory. It was, therefore. predicted that they would judge some sentences which were repeated with a different intention as being different. and would identify the appropriate intention for the sentences. Since. in spontaneous dialogue. speakers tend to remember the form of what they have just said better than what they have just been told (Jarvella. 1972), it was also expected that $S$ s would remember their own sentences from the acted dialogues best.

\section{EXPERIMENT I}

\section{Method}

Two pairs of dialogues were constructed. One dialogue in each pair served as a script for pairs of $S$ s to act ont unrehearsed. and 
Table 1

Sentences Used With Two Intentions

\begin{tabular}{ll}
\hline \multicolumn{1}{c}{ Sentence } & \multicolumn{1}{c}{ Intentions } \\
\hline The door is open. & Statement, Request \\
The food is on the table & Statement, Invitation \\
I'm always here. & Complaint, Invitation \\
You left the light on. & Congratulations, Criticism \\
I should have arrived on time. & Statement, Apology \\
Where will you get the money? & Question, Denial \\
I've never seen you wear that before. Compliment, Insult \\
How kind you are! & Thanks, Sarcasm \\
\hline
\end{tabular}

the other served as a comparison passage for subsequently testing their sentence recognition. In each comparison passage, 20 sentences were underlined and followed by blank spaces for $S s$ to record same-different judgments. A total of 40 sentences were thus underlined. Of these sentences, 8 were identical in content, form, and intention to acted sentences, 8 differed in form alone, 8 differed in intention alone, and 16 were completely novel. Table 1 shows the eight sentences which were repeated with a different intention across dialogues. The grammatical complexity and length of these sentences, as well as the range of intentions shown, are representative of the other test items. In the two instances of all 16 repeated sentences, propositional content was made completely identical to rule out any effect of ambiguous reference on recognition judgments.

The speaker-hearers were 24 female students enrolled in introductory psychology courses at Case Western Reserve University. Testing was conducted in a small experimental room with single pairs of Ss seated face-to-face across a table. Each acted and comparison passage contained 32 utterances and about 600 words shared equally by two speakers, A and B. In each comparison passage, exactly half of the identical sentences and those changed only in form or in intention corresponded to each speaker's part in the previous acted dialogue. The Ss were instructed to attend to the meaning of both what they said and what they heard during each acted dialogue, and to read carefully through each subsequent comparison passage as they recorded their same-different judgments. These judgments were to be based on whether each underlined sentence was the same as any acted sentence or different.

\section{Results and Discussion}

Table 2 shows the percentage of "same" judgments obtained in each experimental condition. Three main results will be described. First, same judgments were the dominant response in all conditions in which the content of acted sentences was repeated in comparison items. Overall, $78 \%$ of the sentences with repeated content were judged as being the same vs only $7 \%$ of those with novel content. This result replicates the main finding of Sachs (1967) in a context where Ss served both as speakers and hearers. The magnitude of the difference obtained for content, moreover, indicates that Ss used propositional content rather than intention or form as their main criterion in making judgments.

Second, statistically reliable differences were nonetheless obtained among the percentages of same judgments for the three main types of sentences with repeated content. Of these, sentences with the same form and intention as acted sentences were rated as being the same $88 \%$ of the time. The corresponding sentences differing only in form from acted sentences were rated as the same $69 \%$ of the time, and those differing only in intention, $77 \%$ of the time. Significantly more same judgments were made on the fully identical sentences than on either set of partly changed ones $(p<.01$ for each by one-tailed sign tests by Ss). Interestingly, the difference obtained between the identical and changed sentences in each case appears to have been mainly a function of the communication situation employed. Basically the same results were obtained when the experiment was repeated using different speaker-hearers and a different set of materials. However, when still different listeners rated the same materials after hearing a tape recording of each acted dialogue, somewhat different results were forthcoming. In that case, $86 \%$ of the items differing in intention alone were judged as being the same, vs $73 \%$ of both the identical items and those differing only in form and $14 \%$ of the items with novel content. Both form and intention therefore seemed to influence sentence recognition judgments more when Ss were required to act out the conversations than when they were permitted to listen passively. Although Ss' acting was not rated systematically, the better actors also seemed to reject more sentences changed in intention or form.

Third, about $10 \%$ more same judgments were obtained for sentences with repeated content when Ss had spoken the original sentences than when they had been addressed the sentences. This trend occurred in each of the three conditions where sentence content was repeated and was significant overall $(\mathrm{p}<.01$ by one-tailed sign test by Ss). This result, together with a previous one for form (Jarvella, 1972) and a third for intention (Experiment II), suggests that speakers may remember most aspects of their own sentences from a conversation somewhat more accurately than would the person(s) with whom they are talking.

\section{EXPERIMENT II}

The previous study indicated that speaker-hearers may not recognize some sentences from a conversation they have just had if the form or intentions for these sentences are altered in the recognition context. The finding for intention suggests indirectly that Ss may remember the intentional meaning for sentences that have occurred, and may reject on this basis sentences which are otherwise the same. Since propositional content seemed to have such a strong effect on sentence recognition judgments, a more direct test of whether

Table 2

Percentage of "Same" Judgments Made in Experiment I

\begin{tabular}{lcccc} 
& \multicolumn{3}{c}{ Content Repeated } & \\
\cline { 2 - 4 } S's Role & $\begin{array}{c}\text { Same Form } \\
\text { Intention }\end{array}$ & $\begin{array}{c}\text { Different } \\
\text { Form }\end{array}$ & $\begin{array}{c}\text { Different } \\
\text { Intention }\end{array}$ & $\begin{array}{c}\text { Content } \\
\text { Novel }\end{array}$ \\
\hline Speaker & 91.7 & 75.6 & 80.2 & 7.4 \\
Hearer & 85.4 & $63.6_{1}$ & 73.0 & 7 \\
\hline
\end{tabular}


speaker-hearers process and remember the intentions for sentences was conducted. In a second study, pairs of female Ss again acted out dialogues. The Ss were subsequently asked to choose between two intentions suggested for some of the sentences from each dialogue. It was predicted that the Ss would recognize and choose the appropriate intentions given for the sentences. These choices were expected to be somewhat more accurate for sentences which Ss had spoken than for those that had been addressed to them.

\section{Method}

The four dialogues constructed for Experiment I were used as separate scripts for pairs of Ss to act out unrehearsed. Following each of two acted dialogues (one from each pair), Ss were given a test form containing the eight sentences which were repeated in the same form in the comparison passage. Short descriptions were printed below each sentence. suggesting two different intentions. For the sentences shown in Table 1. these descriptions were based directly on the intentions shown, stated as precisely as possible and without any disambiguating context. For example. the intentions suggested for the sentence "You left the light on" were "Speaker was congratulating listener for leaving the light on" and "Speaker was criticizing listener for leaving the light on. "For the sentences not shown in Table 1 (those used with the same intention in both dialogues). the appropriate intention and an inappropriate one were likewise described. The order of the two descriptions for each sentence and of the sentences on the test form were counterbalanced and randomized

The speaker-hearers were 24 new female students enrolled in introductory psychology courses at Case Western Reserve University. Tesing was again conducted with single pairs of Ss seated face-to-face. Each pair of Ss acted out one dialogue from each pair: the instructions given for this part of the task were the ame as in Experiment I. After each acted dialogue. the Ss were shown the recognition items and told that they came from the dialogue that had just been acted out. The Ss' task was to mark the description for each sentence which most closely agreed with the meaning of the sentence in the dialogue.

\section{Results and Discussion}

Table 3 shows the percentage of correct recognition judgments obtained for the intentions described. Two main results were obtained. First. in the vast majority of cases, the correct intention for each sentence from the dialogue was identified. For the sentences used with both intentions given in descriptions, $86 \%$ of the recognition responses were correct vs $50 \%$ expected by chance ( $p<.01$ by one-tailed sign test by Ss). Similarly. $96 \%$ of the responses were correct for items used with the same intention in both dialogues. When the experiment was repeated with passive listeners hearing tape recordings of the acted dialogues. the corresponding percentages were $86 \%$ and $100 \%$ correct. The few errors obtained for both speaker-hearers and passive listeners were almost all made on items where one intention was related to the general form of the sentence and the other to a more specific usage. Usually. these errors were in the direction predicted br the sentence's form (e.g.
Table 3

Percentage of Correct Intentions Chosen in Experiment II

\begin{tabular}{lcc} 
& \multicolumn{2}{c}{ Number of Intentions for Sentence } \\
S's Role & 1 & 2 \\
\hline Speaker & 98.0 & 93.8 \\
Hearer & 93.8 & 79.2 \\
\hline
\end{tabular}

"stating" rather than "inviting" for the second declarative sentence in Table 1).

This result further suggests that Ss may remember the intentions for sentences they have used or heard in conversations. While the Ss in the earlier study usually ignored implied differences in intention in favor of repeated content, in this study they were quite accurate in matching explicit intentions with test sentences. This performance does seem to indicate some use of memory for intention which is correlated with propositional content. There are, however, several ways in which Ss might have stored and utilized this correspondence. Assuming that Ss recognized the intentions for particular sentences initially, content and intention for these sentences may have been stored together in memory. Since both these aspects of meaning were identified in test items, the Ss may have simply needed to verify the correct pairing against their memory. On the other hand, suppose that content and intention were stored independently in forms related to the dialogue as a whole. Then, later recognition judgments may have depended on inferences about their correlatedness. To decide which intention described was most relevant to a given sentence, Ss may have referred to what was being discussed in the dialogue, what the general intent of each speaker seemed to be, and so forth. Grice (1957), incidentally, has suggested that a similar process characterizes recognizing intentions for sentences when they are heard. In any case, it seems plausible that some judgments made in Experiment II were true recognitions while others were based on later inferences.

Finally, Ss again made about $10 \%$ fewer errors on items which they had spoken than on items which had been spoken to them ( $\mathrm{p}<.01$ by one-tailed sign test by Ss). This result suggests that the intentions for some sentences were perhaps never communicated. Since a similar speaker-hearer difference was obtained in Experiment I for content, it seems likely that participants in an (acted) conversation may remember more information than is actually communicated, or that they may attend more to what they say than to what they are told. Losses of information through speech might occur, for example, when utterances are more ambiguous in content or function than a speaker intends. On the other hand, a speaker might typically concentrate more on expressing and monitoring his own ideas than on fully processing those expressed to him.

\section{REFERENCES}

Alston. W. P. Philosophy of language. Englewood Cliffs. X.J: Prentice-Hall. 1964 
Austin. J. L. How to do things with words. New York: Oxford Liniversity Press. 1962.

Bransford. J. D.. Barclay. J. R.. \& Franks, J. J. Sentence memory: A constructive versus an interpretive approach. Cognitive Psychology, 1972, 3, 193-209.

Grice, H. P. Meaning. Philosophical Review, 1957, 66, 377.388.

Jarvella. R. J. Syntatic processing of connected speech. Journal of Verbal Learning \& Verbal Behavior, 1971, 10, 409-416.

Jarvella. R. J. Speech processing memory. Paper presented at the International Conference on Speech Communication \& Processing, Boston, April 1972.

Jarvella. R. J. Coreference and short-term memory for discourse. Journal of Experimental Psychology, 1973, 98, 426-428.

Mathewson. G. C., \& Keeney, T. J. Memory for form and meaning of sentences heard in paragraph contexts. Paper presented at the Western Psychological Association. San Francisco. April 1971.
Miller. G. A. Four philosophical problems of psycholinguists. Philosophy of Science, 1970, 37. 183-199.

Robinson, W. P. Langrage and social behavior. Baltimore. Md: Penguin, 1972.

Sachs, J. S. Recognition memory for syntactic and semantic aspects of connected discourse. Perception \& Psychophysics, $1967,2,437-442$.

Searle, J. What is a speech act? In M. Black (Ed.). Philosophy in America. Ithaca, N.Y: Comell University Press, 1965.

Strawson. P. F. Intention and convention in speech acts. Philosophical Review, 1964. 73. 439-460.

(Received for publication May 16, 1973; revision received July 26.1973. ) 